\title{
Knowledge, attitudes and practices of malaria transmission and preventive measures in Woreta town, Northwest Ethiopia
}

Amir Alelign ${ }^{1,2^{*}}$ and Beyene Petros ${ }^{1}$

\begin{abstract}
Objective: Despite a high public health burden of malaria in endemic regions of Ethiopia, there are limitations on the availability of data concerning public awareness about the disease and its preventive measures. The present study aimed in producing base line data on the community knowledge, attitudes and practices towards malaria transmission and its preventive measures in Woreta town, northwest Ethiopia. A community based two-stage random cluster study was conducted from May to July 2013. Household heads were interviewed to assess their awareness about malaria and its control measures.

Results: About $78.5 \%$ (113/144) of the respondents rated bite of infected mosquito as a way of malaria transmission. The majority of participants, $126(87.5 \%)$ stated one or more symptoms of malaria. About $95.8 \%(138 / 144)$ of the respondents indicated that malaria is preventable and curable disease. Only about 25\% (36/144) of the study participants practiced frequent and proper use of insecticide treated bed nets (ITNs). Draining logged water was a highly rated, 83 (57.6\%), practice of environmental management of malaria.
\end{abstract}

Keywords: Malaria, Awareness, Woreta, Ethiopia

\section{Introduction}

Malaria remained to be one of the most sever public health problem worldwide, particularly, in poor tropical and subtropical areas. In 2016, an estimated 445,000 people died of malaria, most were young children in sub-Saharan Africa [1]. Despite the implementation of preventive and control efforts against malaria for decades, it remained to be the leading communicable disease seen at health facilities in Ethiopia [2]. The major intervention strategies that were applied in the country to combat malaria were: early diagnosis and prompt treatment, selective vector control that involves use of indoor residual spraying (IRS), insecticide-treated mosquito nets (ITNs) and environmental management [3]. However, all these efforts were not based on active participation and knowhow of the local community. Hence, an integrated

\footnotetext{
*Correspondence: aleamiro2009@gmail.com

1 Department of Microbial, Cellular and Molecular Biology, Addis Ababa University, P.O. Box 1176, Addis Ababa, Ethiopia

Full list of author information is available at the end of the article
}

effort that actively involves the local communities with their full knowledge is essential to enhance the disease controlling program in malaria endemic regions of the country.

From different parts of Africa, including Ethiopia, considerable number of community-based studies were conducted about the level of awareness about malaria and associated risk factors to its transmission and control measures [4-13]. These studies concluded that misconceptions concerning malaria still exist and that practices for the control of malaria have been unsatisfactory. Therefore, enhancing awareness, beliefs and practices of the community with respect to the disease as well as the identification of special factors contributing to its transmission is required. Thus, the present study aimed to collect baseline information concerning knowledge, attitudes and practices of people in Woreta town, northwest Ethiopia regarding malaria and its preventive measures. Moreover, the study assessed the associated risk factors to the transmission of the disease.

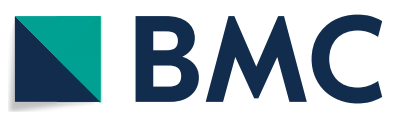

C The Author(s) 2018. This article is distributed under the terms of the Creative Commons Attribution 4.0 International License (http://creativecommons.org/licenses/by/4.0/), which permits unrestricted use, distribution, and reproduction in any medium, provided you give appropriate credit to the original author(s) and the source, provide a link to the Creative Commons license, and indicate if changes were made. The Creative Commons Public Domain Dedication waiver (http://creativecommons.org/ publicdomain/zero/1.0/) applies to the data made available in this article, unless otherwise stated. 


\section{Main text \\ Methods}

\section{Study design and population}

A community based two-stage random cluster study was conducted from May to July 2013 at Woreta town. Woreta is known for its flat and low land regarded as malarious area. Malaria was the most prevalent seasonal disease in the area, and October to December was the peak transmission season [14]. A total of 144 households were selected using probability proportion to size of households in four 'Kebeles' (the smallest administrative units) of the town. The shared households for each Kebeles were divided by the total number of households in a given kebele to determine a sampling interval for selecting households. Accordingly, every 15 th households was selected using systematic random sampling technique [4]. The study population included those aged 15 years and above of both sexes.

\section{Data collection}

A structured questionnaire was designed and administered by data collectors (Additional file 1). The questioner was first developed in English and then translated into 'Amharic', the local language. The household heads were interviewed on their awareness, attitudes and practices towards malaria transmission and its preventive methods. A person who had been thought as the primary decision maker in the family was considered as the head of the household. Whereas, a household was defined as a group of individuals living together in a house and sharing common facilities [15]. In case of the household head absence, a responsible adult above 15 years old who was appointed by the family was interviewed.

\section{Data quality control}

Before starting the actual work, the quality of the questioners was checked for serial number, quantity and procedure of collection. Pre-test was conducted on 5\% of the sample size at each 'kebele' to ensure the validity of the data collection and to standardize the questionnaire. The first author checked the questionnaires for completeness every day. Incomplete questionnaires were returned to data collectors for correction by revisiting the households.

\section{Data analysis}

The data were double entered in Microsoft Excel data sheets and analyzed using SPSS 16 software. Descriptive statistics were carried out to measure relative frequencies, percentages, averages, and relative frequencies of the variables. The risk factor analysis to the number of malaria illness and repeated exposure was done using univariate analysis at $95 \%$ confidence interval (CI) for odds ratio and $\mathrm{p}$-values $<0.05$ were considered to be statistically significant.

\section{Results}

Knowledge, attitude and practices of household respondents towards malaria

About 68.5\% (99/144) of the respondents stated mosquito as cause of malaria and only $24.3 \%$ (35/144) of them rated plasmodium parasite as cause of malaria. Drinking unsafe water and eating contaminated food were also considered to be means of malaria transmission by $11.1 \%$ $(16 / 144)$ and $6.9 \%(10 / 144)$ of the respondents, respectively. Bite of infected mosquito was most rated, 113 $(78.5 \%)$ as a way of malaria transmission (Table 1$)$. The majority of respondents, $126(87.5 \%)$ stated one or more symptoms of malaria and fever was the most frequently stated, 49 (34\%) characteristic followed by shivering, 36 (25\%). Only about $12.5 \%(18 / 144)$ of the respondents did not know how malaria was characterized.

About $95.8 \%(138 / 144)$ of the respondents stated malaria as a preventable and curable disease and $120(83.4 \%)$ of them had encountered malaria illness repeatedly for two or more times in their life time. All of the respondents replied that they possessed at least one insecticide-treated mosquito net (ITN) in their houses. Out of which, only 36 (25\%) of them used ITNs frequently in their house to prevent mosquito bite. The three main components of the environmental management activities in the control of malaria vector were draining logged water, environmental clearing

\begin{tabular}{llc}
$\begin{array}{l}\text { Table } 1 \text { Knowledge and attitudes of respondents related } \\
\text { to the cause, transmission and symptoms of malaria } \\
(\mathbf{N}=\mathbf{1 4 4}) \text {, Woreta town, Northwest Ethiopia, } \mathbf{2 0 1 3}\end{array}$ \\
\hline Characteristics & Categories & Frequency (\%) \\
\hline Cause of malaria & Mosquitoes & $99(68.5)$ \\
& Plasmodium & $35(24.3)$ \\
& Worms & $8(5.6)$ \\
& Unknown & $2(1.4)$ \\
Ways of malaria transmission & Bite of mosquitoes & $113(78.5)$ \\
& Unsafe water & $16(11.1)$ \\
& Contaminated food & $10(6.9)$ \\
& Personal contact & $5(1.1)$ \\
Symptoms of malaria & Fever & $49(34.0)$ \\
& Shivering & $36(25.0)$ \\
& Sweating & $21(4.6)$ \\
& Head ache & $18(12.5)$
\end{tabular}

$\mathrm{N}=$ total number of respondents 
and educating other people to create awareness on malaria and its control methods. Of which, draining logged water was the activity most respondents, 83 (57.6\%) were participated (Table 2).

Table 2 Practices and attitudes of respondents towards control and preventive measures of malaria, Woreta town, Northwest Ethiopia, 2013

\begin{tabular}{llc}
\hline Characteristics & Categories & Frequency (\%) \\
\hline Malaria is preventable and curable & Yes & $138(95.8)$ \\
& No & $6(4.2)$ \\
Type of antimalarial drug used & Chloroquine & $48(33.3)$ \\
& Coartem $^{\circledR}$ & $68(47.2)$ \\
& Other antimalarials & $28(19.4)$ \\
Use of at least one ITNs in the & Yes & $144(100)$ \\
house & No & $0(0)$ \\
Trend in the use of ITNs & Always & $36(25.0)$ \\
& Sometimes & $98(68.1)$ \\
Practice in malaria control activi- & Do not use & $10(6.9)$ \\
ties & Draining logged & $83(57.6)$ \\
& water & \\
& Environmental & $39(27.1)$ \\
& clearing & \\
& Educating people & $22(15.3)$ \\
\hline
\end{tabular}

\section{Risk-factor analysis for malaria illnesses}

Although there were no significant differences between the risk factors to the previous illnesses of malaria, it was comparable among some of the different factors (Table 3). The odds of previous malaria illness was lower among communities within age groups $30-45$ years than those of above 29 years (crude odds ratio [COR]; 0.78, 95\% confidence interval [CI] 0.251-2.468). Similarly, the chance of having previous malaria illnesses was lower in government employees when compared to those engaged in private businesses (COR; 0.39, 95\% CI 0.1014-1.492). No comparable differences in their previous malaria exposure had been noticed between males and females in the community (COR; 1.04, 95\% CI 0.4095-2.634). However, the odds of previous malaria illnesses were higher in non-educated individuals than those who had formal or informal education (COR; 1.59, 95\% CI 0.5036-5.042). In this analysis, considering religion as a risk factor for the previous malaria illness, Muslims had higher odds than Orthodox Christians (COR; 1.57, 95\% CI 0.5183-4.745) (Table 3).

\section{Discussion}

The findings of this study showed that general awareness about malaria and its control methods was high among Woreta town communities. About $78.5 \%$ of the study

Table 3 The distribution of some selected socio-demographic risk factors univariate analysis for previous illness of malaria among respondents, Woreta town, Northwest Ethiopia, 2013

\begin{tabular}{|c|c|c|c|c|c|c|}
\hline \multirow[t]{4}{*}{ Variables } & \multirow[t]{4}{*}{ Categories } & \multirow[t]{4}{*}{ Frequency (\%) } & \multicolumn{3}{|c|}{ Independent effects } & \multirow[t]{4}{*}{ p-value } \\
\hline & & & \multicolumn{3}{|c|}{ House hold respondents $(N=144)$} & \\
\hline & & & Yes & No & Crude OR & \\
\hline & & & n (\%) & n (\%) & $(95 \% \mathrm{Cl})$ & \\
\hline \multirow[t]{4}{*}{ Age (years) } & $15-29^{\mathrm{a}}$ & $32(22.2)$ & $27(84.4)$ & $5(15.6)$ & 1.00 & \multirow[t]{4}{*}{0.84} \\
\hline & $30-45$ & $63(43.8)$ & $51(81.0)$ & $12(19.0)$ & $0.78(0.251-2.468)$ & \\
\hline & $46-60$ & $33(22.9)$ & 29 (87.9) & $4(12.1)$ & $1.34(0.326,5.529)$ & \\
\hline & $>60$ & $16(11.1)$ & $13(81.3)$ & $3(18.7)$ & $0.80(0.1658,3.883)$ & \\
\hline \multirow[t]{2}{*}{ Educational status } & Educated $^{a}$ & $111(77.1)$ & $91(82.0)$ & $20(18.0)$ & 1.00 & \multirow[t]{2}{*}{0.44} \\
\hline & Non-educated & $33(22.9)$ & 29 (87.9) & $4(12.1)$ & $1.59(0.5036,5.042)$ & \\
\hline \multirow[t]{2}{*}{ Sex } & Male $^{a}$ & $47(32.6)$ & $39(83.0)$ & $8(17.0)$ & 1.00 & \multirow[t]{2}{*}{0.92} \\
\hline & Female & $97(67.4)$ & $81(83.5)$ & $16(16.5)$ & $1.04(0.4095,2.634)$ & \\
\hline \multirow[t]{4}{*}{ Occupation } & Private business ${ }^{\mathrm{a}}$ & $43(29.9)$ & $36(83.7)$ & $7(16.3)$ & 1.00 & \multirow[t]{4}{*}{0.32} \\
\hline & GO employee & $15(10.4)$ & $10(66.7)$ & $5(33.3)$ & $0.39(0.1014,1.492)$ & \\
\hline & Daily laborer & $29(20.1)$ & $25(86.2)$ & $4(13.8)$ & $1.22(0.3214,4.596)$ & \\
\hline & House wife & 57 (39.6) & 49 (86.0) & $8(14.0)$ & $1.19(0.3957,3.584)$ & \\
\hline \multirow[t]{3}{*}{ Religion } & Orthodox ${ }^{a}$ & $76(52.8)$ & $63(82.9)$ & $13(17.1)$ & 1.00 & \multirow[t]{3}{*}{0.41} \\
\hline & Muslim & $43(29.9)$ & 38 (88.4) & $5(11.6)$ & $1.57(0.5183,4.745)$ & \\
\hline & Protestant & $25(17.4)$ & $19(76.0)$ & $6(24.0)$ & $0.65(0.2186,1.953)$ & \\
\hline
\end{tabular}

$n$ number of respondents for the category, $O R$ odds ratio

a Reference category 
participants associated mosquito bite to malaria. This was a little higher than a study reported in Jimma town (71.8\%), the other part of Ethiopia [16]. About $24 \%$ of the respondents were aware of plasmodium parasites as the cause of malaria. The possible explanation about the poor knowledge on the cause of malaria could be misconceptions about causes and ways of transmission of malaria. Their previous knowledge in associating malaria with mosquito bite might have influenced some members of the community. Misconceptions about cause of malaria were also reported in other similar studies $[17,18]$.

The knowledge of respondents whether malaria is preventable and curable was very high $(95.8 \%)$. In agreement, other studies conducted in Ethiopia reported higher knowledge of communities on malaria as preventable and curability $[4,19]$. About 57.6 and $27.1 \%$ of the respondents were engaged in malaria control activities in the community through draining logged water and environmental clearing, respectively. The observed participation in control activities was lower than reports from studies of other areas in Ethiopia, 73\% in town and $26.9 \%$ in rural areas $[8,20]$. Such differences in the practice of managing malaria might be due to differences in awareness on the transmission methods of the disease and differences in the leadership efforts to mobilize communities to participate in the malaria control activities among the different study areas.

All the respondents possessed at least one ITN in their house. However, the majority of them (68.1\%) were not frequently using the bed nets. Despite the availability of the nets, misuse of them was noticed as it had been observed in other studies in some parts of Africa [21-23]. Failure in the use of possessed nets among the community might have been due to lack of awareness on its proper use and its effectiveness in preventing mosquito bite.

Previous reports suggested that malaria prevalence had been influenced by other socio-demographic factors $[24,25]$. In our study, there were comparable differences within some of the socio-demographic characteristics such as age, educational status, occupation, sex and religion of the respondents; however, no significant difference was observed. This lack of significant difference might have been due to the fact that some other potential factors such as mismanagement of the ongoing massive rice irrigation activity might have contributed for the occurrence of the disease in the study area.

\section{Conclusion}

Overall, awareness about malaria and its control measures was high among Woreta town community. Despite this, occasional use of ITNs was observed to be one of the major setbacks for the effort to control the decrease. Therefore, awareness campaign should be strengthened in this respect.

\section{Limitation}

The present study was limited in assessing the influence of other factors such as nutritional status and indications of co-infections which may have contributed for the occurrence of the disease.

\section{Additional file}

Additional file 1. Semi-structured questionnaire for respondents of Woreta town, Fogera district, northwest Ethiopia: the questionnaire was designed to collect data on knowledge, attitudes and practices on malaria transmission and control measures. It contained three components; (a) instruction to the respondents, (b) socio-demographic characteristics of respondents and (c) participants' knowledge, attitudes and practices on malaria transmission and its prevention.

\section{Abbreviations}

$\mathrm{Cl}$ : confidence interval; CQ: chloroquine; DDT: dichloro diphenyle trichloro ethane; HHs: house holds; IRS: indoor residual spraying; ITNs: insecticidetreated mosquito nets; KAPs: knowledge, attitudes and practices; OR: odds ratio; SPSS: statistical package for the social sciences.

\section{Authors' contributions}

AA performed data collection, analyzed the results and wrote the paper; BP initiated the study and made major contribution in the study design, editing and development of the study. Both authors read and approved the final manuscript.

\section{Author details}

${ }^{1}$ Department of Microbial, Cellular and Molecular Biology, Addis Ababa University, P.O. Box 1176, Addis Ababa, Ethiopia. ${ }^{2}$ Department of Biology, Debrebirhan University, P.O. Box 445, Debrebirhan, Ethiopia.

\section{Acknowledgements}

The authors are grateful to the Addis Ababa University, College of Natural Sciences for sponsoring this study. We would like also extend our deepest gratitude to Woreta health center working staff and administrators for providing malaria data and other relevant information for the development of this study.

\section{Competing interests}

The authors declare that they have no competing interests.

\section{Availability of data and materials}

The datasets generated and/or analysed during the current study are available from the corresponding author on reasonable request.

\section{Consent for publication \\ Not applicable.}

\section{Ethics approval and consent to participate}

Ethical clearance for the study was obtained from the Ethical Committee of Addis Ababa University, Department of Microbial, Cellular and Molecular Biology (Ref. CNSDO/491/07/15). In addition, the purpose and objective of the study was explained to administrative health officials and study participants in the study area. As the outcome of the study had no any personal risks/ adverse reactions, and by the choice of the respondents, a verbal consent was sought to undertake the study. In case of participants under the age of 16, consent was obtained from their parents/guardians. The procedure had been agreed with the ethics committee in advance. Confidentiality issues of study participants about the results were kept. 


\section{Funding}

All the financial support for the study's data collection, analyzing and writing up the research paper was obtained from the thematic area projects of Addis Ababa University, college of natural science, with Grant Number GSR/2748/05.

\section{Publisher's Note}

Springer Nature remains neutral with regard to jurisdictional claims in published maps and institutional affiliations.

Received: 14 June 2018 Accepted: 13 July 2018

Published online: 18 July 2018

\section{References}

1. WHO. World malaria report 2017. World Health Organization. http://www. who.int/malaria/publications/world-malaria-report-2017/en/. Accessed 30 July 2018.

2. MOP. Malaria operational plan Ethiopia. President's malaria initiative. 2012;55-68. https://www.pmi.gov/docs/. Accessed 9 Jan 2013.

3. $\mathrm{FMoH}$. Health and health related indicators report. Federal Ministry of Health, AddisAbaba, Ethiopia. 2010. https://www.dktethiopia.org/. Accessed 4 Dec 2014

4. Alemu A, Muluye D, Mihret M, Adugna M, Gebeyaw M. Ten year trend analysis of malaria prevalence in Kola Diba, North Gondar, Northwest Ethiopia. Parasites Vector. 2012;5:173.

5. Abate A, Degarege A, Erko B. Community knowledge, attitude and practice about malaria in a low endemic setting of Shewa Robit Town, Northeastern Ethiopia. BMC Public Health. 2013;13:312.

6. Mazigo H, Obasy E, Mauka W, Manyiri P, Zinga M, Kweka E, Mnyone L, Heukelbach J. Knowledge, attitudes, and practices about malaria and its control in rural Northwest Tanzania. Malar Res Treat. 2010. https://doi org/10.4061/2010/79426.

7. Ayele D, Zewotir T, Mwambi H. Prevalence and risk factors of malaria in Ethiopia. Malar J. 2012;11:195.

8. Deressa W, Ali A, Enquoselassie F. Knowledge, attitude and practice about malaria, mosquito and antimalarial drugs in rural community. Ethiop J Health Dev. 2003;17(Suppl 2):99-104.

9. Legesse M, Deressa W. Community awareness about malaria, its treatment and mosquito vector in rural highlands of central Ethiopia. Ethiop J Health Dev. 2009;23(Suppl 1):40-7

10. Legesse $Y$, Tegegn A, Belachew T, Tushune K. Knowledge, attitude and practice about malaria transmission and its preventive measures among households in Urban Areas of Assosa Zone, Western Ethiopia. Ethiop Health Dev. 2007;21(Suppl 2):157-65.
11. Astatkie A. Knowledge and practice of malaria prevention methods among residents of Arba Minch Town and Arba Minch Zuria District, Southern Ethiopia. Ethiop J Health Sci. 2010;20(Suppl 3):185-93.

12. Erhun $\mathrm{O}$, Agbani $\mathrm{O}$, Adesanya O. Malaria prevention: knowledge, attitude and practice in a Southwestern Nigerian community. Afr J Biomed Res. 2005;8:25-9.

13. Safari K, Fabian M, Joseph M, Soori N, Godfrey K, Robert M, et al. Knowledge, attitudes and practices about malaria among communities: comparing epidemic and non-epidemic prone communities of Muleba district, Northwestern Tanzania. BMC Public Health. 2010;10:395.

14. NWZMS. Rainfall and temperature records for Woreta station. North Western Zone Meteorological Services, Amhara region, Bahir Dar; 2004.

15. Mazigo H, Obasy E, Mauka W, Manyiri P, Zinga M, Kweka E, Mnyone L, Heukelbach J. Knowledge, attitudes, and practices about malaria and its control in rural Northwest Tanzania. Malar Res Treat. 2010. https://www. hindawi.com/journals/mrt/2010/. Accessed 15 Apr 2013.

16. Alemu A, Tsegaye W, Golassa L, Abebe G. Urban malaria and associated risk factors in Jimma town, Southwest Ethiopia. Malar J. 2011;10:173.

17. Ahmed S, Haque R, Haque U, Hossain A. Knowledge on the transmission, prevention and treatment of malaria among two endemic populations of Bangladesh and their health-seeking behavior. Malar J. 2009;8(1):173.

18. Wakgari D, Ahmed A, Damen H. Malaria related health seeking behavior and challenges for care providers in rural Ethiopia implications for control. J Biosoc Sci. 2008;40:1-21.

19. Abate A, Degarege A, Erko B. Community knowledge, attitude and practice about malaria in a low endemic setting of Shewa Robit Town, northeastern Ethiopia. Public Health. 2013;13:312.

20. Tilaye T, Deressa W. Prevalence of urban malaria and associated factors in Gondar Town, Northwest Ethiopia. Ethiop Med J. 2007:45:151-8.

21. Lines D, Myamba J, Curtis F. Experimental hut trials of permethrin impregnated mosquito nets and eave against malaria vectors in Tanzania. Med Vet Entomol. 1987;1:37-51.

22. Brieger R, Onyido E, Sexton D, Ezike I, Breman G, Ekanem J. Monitoring community response to malaria control using insecticide impregnated bed nets, curtains and residual spray at Nsukka, Nigeria. Health Educ Res. 1996;11(Suppl 2):133-45.

23. Adeyemi S, Adekanle A, Akintola E. Use prevalence of insecticide treated mosquito bed nets among pregnant population in Osogbo, Nigeria. Niger Med Pract. 2007;52:29-32

24. Fuge T, Ayanto S, Fiseha L, Gurmamo F. Assessment of knowledge, attitude and practice about malaria and ITNs utilization among pregnant women in Shashogo District, Southern Ethiopia. Malar J. 2015:14:235.

25. van Genderen P, Mulder P, Overbosch D. The knowledge, attitudes and practices of winter sun vacationers to the Gambia toward prevention of malaria: is it really that bad? Malar J. 2014;13:74.
Ready to submit your research? Choose BMC and benefit from:

- fast, convenient online submission

- thorough peer review by experienced researchers in your field

- rapid publication on acceptance

- support for research data, including large and complex data types

- gold Open Access which fosters wider collaboration and increased citations

- maximum visibility for your research: over 100M website views per year

At BMC, research is always in progress.

Learn more biomedcentral.com/submissions 